\title{
Emergency Department Management Metrics for Severe Pediatric Traumatic Brain Injury
}

\author{
Maple Liu \\ University of Saskatchewan College of Medicine \\ Tanya Holt \\ University of Saskatchewan College of Medicine \\ Gregory Hansen ( $\sim$ gregory.hansen@usask.ca ) \\ University of Saskatchewan College of Medicine
}

\section{Original Research}

Keywords: Brain injuries, Children, Traumatic, Quality improvement

Posted Date: August 18th, 2020

DOI: https://doi.org/10.21203/rs.3.rs-58763/v1

License: (1) This work is licensed under a Creative Commons Attribution 4.0 International License. Read Full License 


\section{Abstract}

Background: As the majority of severe pediatric traumatic brain injuries (TBI) are received and managed in the emergency department (ED), the ED trauma center is vital to optimizing management. This study aimed to evaluate current management guidelines, and to recognize other high-risk components of TBI management.

Methods: A retrospective chart review was conducted solely at the Jim Pattison Children's Hospital in Saskatoon, Canada. Data pertaining to emergency department metrics included transport to trauma center, injury severity, indicators for raised intracranial pressure, airway and breathing, circulation, disability/central nervous system, complications, and outcome scores.

Results: A total of 56 charts were included in the study population. Mean age of patient population was 14.3 years of age, with $76 \%$ being male. Thirty four percent of patients received a blood gas within 15 minutes of admission, and $20 \%$ received intervention to correct $\mathrm{PCO}_{2}$. Of the seven patients who received hyperosmolar therapy, three were based on computed tomography (CT) findings and four were based clinically. For $95 \%$ of patients, the position of the bed was not documented, and just $4 \%$ of patients had head of bed elevated to 30 degrees. Sixty four percent of patients were accompanied by a physician with airway expertise during $\mathrm{CT}$.

Conclusions: Building on current TBI guidelines, timeliness of $\mathrm{PCO}_{2}$ retrieval and improvements for targeted hyperosmolar therapy were noted. Two other potential areas for improving management included deliberate considerations for head of bed positioning and personnel accompanying patients undergoing $\mathrm{CT}$.

\section{Background}

Traumatic brain injury (TBI) is the leading cause of residual disability and injury-related mortality in North American children [1-4]. Consequently, it is crucial to understand prognostic factors involved in improving outcomes that can be implemented in the management of this patient population. Although risk factors and mortality in adult TBI have been well studied, evidence in children is less robust [5].

Adherence to severe TBI guidelines [6] in pediatrics has been associated with higher discharge survival and improved Glasgow Outcome Scale (GOS) scores [5]. The emergency department (ED) is an important consideration [2], as it receives and provides timely management to the majority of injuries. To date, there have been two multi-center studies that examined ED adherence to pediatric TBI guidelines. A large multicenter study from Argentina observed 6 ED adherence parameters relating to hypoxia, hypotension, disability, and hyperosmolar therapy [7]. The second was the Pediatric Guideline Adherence and Outcomes Study (PEGASUS) group who included five ED adherence measures relating to management of hypoxia, hypotension, temperature, and hyperosmolar therapy [4]. Although the group from Argentina did not a find significant association between adherence to pediatric TBI guidelines and improved survival and outcome scores, the PEGASUS group did demonstrate a positive association [4.7]. 
Evaluating ED management of severe pediatric TBI with the aforementioned parameters may be missing key elements of care. This retrospective study aimed to expand on published ED adherence parameters through the application of current TBI guidelines [6] and recognition of high-risk components of TBI management in children. Areas of management addressed included; airway and breathing, circulation, disability, investigations, and specific neuroprotective therapies. We hypothesized that areas of ED management could be improved, in a province that has significant barriers regarding lengthy interfacility transports from rural, remote, and isolated communities [8].

\section{Methods}

\section{Study Center}

This study was a retrospective chart review that was conducted at the Jim Pattison Children's Hospital (JPCH) in Saskatoon, Canada.

\section{Population and criteria}

Eligible individuals were identified through medical records and a Pediatric Intensive Care Unit (PICU) registry. Inclusion criteria included: patients $\leq 18$ years, severe TBI defined as Glasgow Coma Scale (GCS) score of $\leq 8$ prior to triage in the JPCH ED, injury from 2010 to time of ethics approval, Head Abbreviated Injury Scale (AIS) score of $\geq 3$, TBI ICD codes (800-801.9, 803-804.9, 850-854.1, or 959.01) and triaged in the ED. Increased intracranial pressure (ICP) at the ED was defined by i) craniotomy with 12 hours of admission; or, ii) herniation syndrome or midline shift $>5 \mathrm{~mm}$ on neuroimaging; or, iii) raised ICP monitoring of $>20 \mathrm{~mm} \mathrm{~cm} \mathrm{H} \mathrm{m}_{2} \mathrm{O}$ within 12 hours of admission. Exclusion criteria included death prior to arrival of ED.

\section{Emergency Department Metrics}

An exhaustive list of potential management indicators was created by a pediatric neurointensivist and neurosurgeon with experience in traumatic brain injury. Indicators and metrics were considered if they were consistent with TBI guidelines, clinically relevant, and accessible through a retrospective chart review. It was then vetted through a focus group which comprised of 3 pediatric intensivists, two neurosurgeons, and four emergency physicians. Modifications to the list ensued, followed by a final focus group review. Items required a $75 \%$ majority to be included.

The final metrics included: a) position of head of bed (HOB); b) position of head (C-spine precaution); ) time of first temperature check; d) temperature treated in 30 minutes if $<36$ or $>37.5^{\circ} \mathrm{C}$; e) hypoxia treated in 30 minutes after onset; f) systemic hypotension [SBP $<70+2$ (age) or MAP $<40+1.5$ (age)] treated within 30 minutes of admission; g) blood gas $\mathrm{CO}_{2}$ obtained within 15 minutes of admission; $\mathrm{h}$ ) $\mathrm{ETCO}_{2}$ monitoring; i) blood gas $\mathrm{CO}_{2}$ corrected within 5 minutes if $<35$ or $>40$; j) clinical seizures treated within 10 minutes of onset; $\mathrm{k}$ ) timing of admission to labs including glucose, $\mathrm{CBC}$, differential and electrolytes; I) timing of admission to computed tomography (CT); m) complications in CT (i.e. herniation, 
unplanned extubation); n) personnel with patient in CT; o) indications to administer hyperosmolar therapy; and, p) timing of admission to either neurosurgical operating room or PICU.

\section{Variables}

Patient identifiers included age, weight, gender, and mechanism of injury (including motor vehicular collision, fall, pedestrian vs. vehicle, gunshot, assault, bicycle). Pre-trauma center metrics included time of injury to arrival at trauma center, distance of scene to trauma center (if beyond urban emergency medical services catchment), and mode of transport (ground, fixed wing, helicopter EMS). Injury severity was documented with Head AIS and Pediatric Risk of Mortality (PRISM) score. Raised ICP at trauma center was defined as craniotomy within 12 hours of admission, raised ICP $>20 \mathrm{~cm} \mathrm{H}_{2} \mathrm{O}$ within one hour of placement, and ED neuroimaging suggesting herniation syndrome or midline shift $>5 \mathrm{~mm}$ ). ED TBI metrics were discussed above. Outcomes included: day 1 mortality, mortality, comfort care at admission, length of PICU stay, length of hospital stay, and GOS scores of survivors.

\section{Statistical Methods}

All analyses were be done using SPSS software. Discrete variables were reported as percentages, and continuous variables were reported as median and interquartile ranges.

\section{Results}

Of the 57 charts identified through the registry, a total of 56 charts were included in the study population. Patient demographics, mechanism of injury and first responder data are summarized in Table 1. Metrics for airway, breathing, circulation and disability are summarized in Table 2. Of note, $34 \%(n=19)$ of patients received a blood gas within 15 minutes of admission and only $20 \%(n=11)$ received interventions to achieve $\mathrm{PCO}_{2}$ between $35-40 \mathrm{mmHg}$. Conversely, with regard to hypotension, the majority received corrective intervention within 15 minutes of identification. The HOB was elevated to 30 degrees for $4 \%(n=2)$ of patients, and was not documented for most $(95 \%)$. Thirteen percent $(n=7)$ of patients demonstrated radiographic signs of herniation on CT. Metrics for CT, and therapies directed at raised ICP is summarized in Table 3. 
Table 1

Patient characteristics and first responder data $(n=56)$.

\section{Demographics}

Age in years*

Male sex, $\mathrm{n}(\%)$

Mechanism of injury

MVC (\%)

Fall, $\mathrm{n}(\%)$

Pedestrian vs vehicle, $\mathrm{n}(\%)$

Recreational vehicle, $\mathrm{n}(\%)$

Sports related, $\mathrm{n}(\%)$

Gunshot, n (\%)

Other, n (\%)

First responder data

$\mathrm{AIS}^{+}$

$\mathrm{PRISM}^{+}$

Location in $\mathrm{km}^{*}$

Lowest GCS ${ }^{+}$

Air transport (\%)

Ground transport (\%)

Intubated prior to arrival (\%)

Event to ED (minutes)*
$14.3 \pm 4.6$

$43(76)$

$25(45)$

4 (7)

$5(9)$

$5(9)$

3 (5)

$1(2)$

9 (16)

$4(2-5)$

$12(7-17)$

$161.8 \pm 125.3$

$3.5(3-6)$

$30(54)$

$26(46)$

$42(75)$

$233.1 \pm 117.1$

*mean \pm standard deviation; ${ }^{+}$median (interquartile range). AIS = abbreviated injury scale, ED $=$ Emergency Department, GCS = Glasgow Coma Scale, MVC = motor vehicle collision, PRISM = Pediatric Risk of Mortality Score. 
Table 2

Measures for airway, breathing, circulation, disability $(n=56)$.

\section{Airway/Breathing}

Intubated in ED, $\mathrm{n}(\%)$

Time of intubation in minutes*

Hypoxia, n (\%)

Hypoxia treated, $\mathrm{n}(\%)$

Blood gas within 15 min., $\mathrm{n}(\%)$

If no blood gas within 15 min., how long in minutes*

$\mathrm{EtCO}_{2}$ obtained, $\mathrm{n}(\%)$

If $\mathrm{EtCO}_{2}$ obtained, how long after intubation in minutes

$\mathrm{CO}_{2}$ corrected, $\mathrm{n}(\%)$

Circulation

Systolic hypotension, $\mathrm{n}(\%)$

Systolic hypotension corrected within 15 min., n (\%)

MAP hypotension, $\mathrm{n}(\%)$

MAP hypotension corrected within 15 min., n (\%)

Disability

Pupils checked, n (\%)

Time of pupil check in minutes*

GCS checked, $\mathrm{n}(\%)$

Position of bed not documented, $n$ (\%)

Position of bed 30 degrees, $n$ (\%)

C-spine precautions, $\mathrm{n}(\%)$

Temperature checked, $\mathrm{n}(\%)$

Temperature not checked, $\mathrm{n}(\%)$

Time of temperature check in minutes*
$48(86)$

$12(21)$

$22.1 \pm 14.7$

$3(5)$

$2(67)$

19 (34)

$39.7 \pm 26.8$

$37(66)$

$13.9 \pm 25.2$

$11(20)$

9 (16.)

6 (67)

7 (13)

7 (100)

$4.8 \pm 12.1$

55 (98)

53 (95)

2 (4)

54 (96)

43 (77)

13 (23)

$21.7 \pm 35.2$

*mean \pm standard deviation. $\mathrm{ED}=$ emergency department; $\mathrm{EtCO}_{2}=$ end-tidal $\mathrm{CO}_{2} ; \mathrm{GCS}=$ Glasgow Coma Scale; MAP = mean arterial pressure. 


\section{Airway/Breathing}

Abnormal temperature treated, $\mathrm{n}(\%)$

Clinical seizures, n (\%)

If seizures, when treatment initiated in minutes*

Laboratory

Labs taken, $\mathrm{n}(\%)$

Time to first labs in minutes*
$6(11)$

$4(7)$

$6.5 \pm 5.2$

$53(95)$

$31.5 \pm 29.4$

*mean \pm standard deviation. $\mathrm{ED}=$ emergency department; $\mathrm{EtCO}_{2}=$ end-tidal $\mathrm{CO}_{2} ; \mathrm{GCS}=\mathrm{Glasgow}$ Coma Scale; MAP = mean arterial pressure.

Table 3

Patient data regarding intracranial pressures and therapies $(n=56)$.

\section{Indicators of raised ICP}

Herniation, $\mathrm{n}(\%)$

$5(8.9)$

Midline shift, n (\%)

2 (3.8)

Emergent craniotomy, n (\%)

$6(10.7)$

CT

Time to CT in minutes*

$77 \pm 29.1$

Personnel: not charted, n (\%)

$31(55.4)$

Personnel: MD with airway expertise, n (\%)

16 of 25 (64)

Complications in CT, n (\%)

$3(5.4)$

Hyperosmolar therapy

Therapy provided, n (\%)

$7(12.5)$

Time to hyperosmolar therapy in min.

$38.6 \pm 15.2$

Indication: CT findings, n (\%)

$3(42.9)$

Indication: clinical, n (\%)

$4(47.1)$

Operating room

Time to neurosurgical OR in minutes

$114 \pm 80.7$

*mean \pm standard deviation. ICP = intracranial pressure; OR = operating room. 
Among the 8 patients (14.3\%) who died in hospital, 5 died on day one of hospital stay. Four patients (7.1\%) required comfort care on discharge. Length of PICU stay and hospital admission averaged 9.5 (SD 8.3) and 22.9 (SD 24.6) days, respectively. Median GOS on discharge was 3 (range 3 to 4.5).

\section{Discussion}

The purpose of this study was to evaluate application of standard therapy guidelines and recognize other risk factors with regard to the management of severe pediatric TBI in the ED. Two key findings from this study relate to metrics outlined in current TBI guidelines; timeliness for retrieval of first $\mathrm{PCO}_{2}$, and indications for hyperosmolar therapy. Two non-guideline metrics showed that the HOB was not elevated in a large majority of our patients, and an inconsistent presence of physicians with airway expertise accompanying patients to the CT scanner.

One of the deficiencies we reported was a timely retrieval of $\mathrm{PCO}_{2}$. Cerebral blood flow varies proportionally with $\mathrm{PCO}_{2}$ and is the most important factor that balances ICP exacerbation with adequate cerebral oxygenation [9]. Although most patients received $\mathrm{EtCO}_{2}$ monitoring within fifteen minutes of ED admission, a blood gas was obtained in only $34 \%$ of our patients during this time, and even fewer received corrections to maintain target normocapnia. Targeted ventilation in the ED has been well documented for optimal discharge outcomes in patients with normocarbia $\left(\mathrm{PaCO}_{2}=36-45 \mathrm{mmHg}\right)$, and increased mortality with hypocapnia and hypercapnia $\left(\mathrm{PaCO}_{2} \leq 35 \mathrm{mmHg}\right.$, and $\geq 46 \mathrm{mmHg}$, respectively) [9]. As important, $\mathrm{EtCO}_{2}$ is not an adequate initial surrogate for $\mathrm{PCO}_{2}$ in pediatric patients with severe TBI, but its trend can be useful between $\mathrm{PCO}_{2}$ retrieval times $[10,11]$.

This study also gathered data around hyperosmolar therapy administration based on clinical and radiological signs of raised ICP. Although the gold standard for ICP monitoring is placement of an intracranial monitor, it is obviously not feasible during the initial resuscitation in the ED $[12,13]$. The most challenging part of targeted hyperosmolar therapy in severe TBI has been the proper identification of increased ICP. Thirteen of our patients received hyperosmolar therapy, with an even split between CT and clinical indication for its use. Clinically changes in Glasgow Coma Scale, pupillary reactivity, and herniation syndrome are often late signs of raised ICP. Radiographically, a CT scan can be inconclusive in quantifying ICP after severe TBI $[13,14]$, unless obvious criteria have been met. Together, they point to the utility of more novel techniques of reliably and rapidly estimating ICPs, such as transcranial dopplers or ultrasonography of optic nerve sheath diameters [12].

Adult ED management guidelines by the Seattle International Brain Injury Consensus Conference included elevation of $\mathrm{HOB}$ to $30-45^{\circ}$ as an intervention [15]. HOB elevation can have beneficial effects on raised ICP by facilitating cerebral blood flow, increasing cerebrospinal fluid drainage, and maximizing cerebral venous return $[16,17]$. Although our study found that only $4 \%$ of patients had their HOB elevated, current pediatric TBI guidelines do not address this potential therapy. Interestingly, the wide range of HOB elevation recommendations in adults is likely indicative of patient height variations and consequential 
hydrostatic differences between skull base and heart level [17]. Given the known beneficial effects of elevating the HOB including lowering ICP as well as other multisystem effects in severe TBI $[18,19]$, we recommend it as a high-level priority in the initial ED management with normotensive patients.

Finally, we identified that brain CT in the ED may require further considerations. Our study found that $5 \%$ of patients experienced adverse events during CT scan, with only $65 \%$ of patients being accompanied by a physician with airway expertise. However, a recent national study examined CT practice standards for severe pediatric TBI across tertiary care centers in Canada, and found that over half of the respondents experienced an adverse event in CT [20]. These events, including airway complications may be avoided with the correct care team at bedside.

Major limitations in this study included the small population cohort, the nature of chart reviews, as well as variability in pre-hospital care. Inherent in a chart-review, data collection relies on accurate chronicling, thus calling to question the certainty regarding absence of the expected management versus failure of documentation. This limitation was especially important regarding HOB position. Lastly, patients arrived to the tertiary care hospital with previous management outside of our documentation parameters. The scope of this study did not include pre-hospital management that may have affected ED management protocols on arrival.

\section{Conclusion}

This study compared ED management of pediatric severe TBI to guidelines, as well as novel parameters shown to affect TBI outcomes in adults. Although there are many areas of adherence to current recommendations, we would suggest further considerations around time metrics for obtaining $\mathrm{PCO}_{2}$, noninvasive bedside evaluations for raised ICP, raised HOB with normotensive patients, and medical personnel for CT scanning.

\section{Declarations}

\section{Availability of Data and Materials}

All data are available from the corresponding author upon request.

\section{Funding}

None

\section{Contributions}

GH and TH conceptualized the study. ML collected data and wrote the initial manuscript. GH conducted data analysis and interpretation. GH approved the final manuscript. All authors read and approved the final manuscript. 


\section{Ethics Approval}

Ethics approval was obtained from the University of Saskatchewan Health Research Ethics Board.

\section{Acknowledgements}

Not applicable.

\section{Competing Interests}

The authors declare no competing interests.

\section{References}

1. Keenan HT, Bratton SL. Epidemiology and outcomes of pediatric traumatic brain injury. Dev Neurosci. 2006;28(4-5):256-63.

2. Langlois JA, Rutland-Brown W, Thomas KE. The incidence of traumatic brain injury among children in the United States: differences by race. J Head Trauma Rehabil. 2005;20(3):229-38.

3. Coronado VG, Xu L, Basavaraju SV, McGuire LC, Wald MM, Faul MD, et al. Surveillance for traumatic brain injury-related deaths - United States, 1997-2007. MMWR Surveill Summ. 2011;60(5):1-32.

4. Vavilala MS, Kernic MA, Wang J, Kannan N, Mink RB, Wainwright MS, et al. Acute care clinical indicators associated with discharge outcomes in children with severe traumatic brain injury. Crit Care Med. 2014;42(10):2258-66.

5. Amagasa S, Tsuji S, Matsui H, Uematsu S, Moriya T, Kinoshita K. Prognostic factors of acute neurological outcomes in infants with traumatic brain injury. Childs Nerv Syst. 2018;34(4):673-80.

6. Kochanek PM, Tasker RC, Carney N, Totten AM, Adelson PD, Selden NR, et al. Guidelines for the Management of Pediatric Severe Traumatic Brain Injury, Third Edition: Update of the Brain Trauma Foundation Guidelines. Pediatr Crit Care Med. 2019;20(3S Suppl 1):1-82.

7. Vavilala MS, Lujan SB, Qiu Q, Petroni GJ, Ballarini NM, Guadagnoli N, et al. Benchmarking prehospital and emergency department care for Argentine Children with traumatic brain injury: for the South American guideline adherence group. PLoS ONE. 2016;11(12):e0166478.

8. Hansen G, Vallance JK. Ventilation Monitoring in Severe Pediatric Traumatic Brain Injury at Nontrauma Centers. Air Med J. 2015;34(5):278-82.

9. Ramaiah VK, Sharma D, Ma L, Prathep S, Hoffman NG, Vavilala MS. Admission oxygenation and ventilation parameters associated with discharge survival in severe pediatric traumatic brain injury. Childs Nerv Syst. 2013;29(4):629-34.

10. Hansen G, Vallance JK. Ventilation monitoring for severe pediatric traumatic brain injury during interfacility transport. Int J Emerg Med. 2015;8(1):41.

11. Martinon C, Duracher C, Blanot S, Escolano S, De Agostini M, Périé-Vintras AC, et al. Emergency tracheal intubation of severely head-injured children: changing daily practice after implementation of 
national guidelines. Pediatr Crit Care Med. 2011;12(1):65-70.

12. Narayan V, Mohammed N, Savardekar AR, Patra DP, Notarianni C, Nanda A. Noninvasive intracranial pressure monitoring for severe traumatic brain injury in children: a concise update on current methods. World Neurosurg. 2018;114:293-300.

13. Pappu S, Lerma J, Khraishi T. Brain CT to assess intracranial pressure in patients with traumatic brain Injury. J Neuroimaging. 2016;26(1):37-40.

14. Vavilala MS, Lujan SB, Qiu Q, Bell MJ, Ballarini NM, Guadagnoli N, et al. Intensive care treatments associated with favorable discharge outcomes in Argentine children with severe traumatic brain injury: for the South American Guideline Adherence Group. PLoS One. 2017;12(12):e0189296.

15. Miles DK, Ponisio MR, Colvin R, Limbrick D, Greenberg JK, Brancato C, et al. Predictors of intracranial hypertension in children undergoing ICP monitoring after severe traumatic brain injury. Childs Nerv Syst. 2020;36(7):1453-60.

16. Tasker RC. Intracranial pressure: influence of head-of-bed elevation, and beyond. Pediatr Crit Care Med. 2012;13(1):116-7.

17. Agbeko RS, Pearson S, Peters MJ, McNames J, Goldstein B. Intracranial pressure and cerebral perfusion pressure responses to head elevation changes in pediatric traumatic brain injury. Pediatr Crit Care Med. 2012;13(1):e39-47.

18. Bennett TD, Statler KD, Korgenski EK, Bratton SL. Osmolar therapy in pediatric traumatic brain injury. Crit Care Med. 2012;40(1):208-15.

19. Fan JY. Effect of backrest position on intracranial pressure and cerebral perfusion pressure in individuals with brain injury: a systematic review. J Neurosci Nurs. 2004;36(5):278-88.

20. Yoo G, Leach A, Woods R, Holt T, Hansen G. Computed tomography practice standards for severe pediatric traumatic brain injury in the emergency department: a national survey. J Child Adol Trauma. 2020. In press. 